\title{
REVISIONES
}

\section{Didáctica de las Artes Visuales, una aproximación desde sus enfoques de enseñanza*}

\author{
Visual Arts Didactics, an approximation from the teaching approaches
}

\author{
Patricia Raquimán Ortega, ${ }^{a}$ Miguel Zamorano Sanhueza ${ }^{a b}$ \\ a'Universidad Metropolitana de Ciencias de la Educación \\ Telf.: (56) 977705640. Correo electrónico: patricia.raquiman@umce.cl \\ bTelf.: (56) 976151950. Correo electrónico: miguel.zamorano@umce.cl
}

\section{RESUMEN}

La definición de conocimiento artístico que se articula en este escrito se sustenta en la existencia de diferentes enfoques que articulan la construcción de marcos de referencia para la formación artística visual de los estudiantes. Se examina la generación de conocimiento artístico a partir de formas de enseñanza de las Artes Visuales dadas a lo largo de ciertos periodos históricos. A través de estos enfoques se desarrolla una visión, desde la Didáctica de las Artes Visuales, considerando algunos atributos que caracterizan la teorización de sus supuestos conceptuales y su implementación en la práctica educativa. Se precisan algunas características que van desde concepciones racionalistas y universalistas hasta miradas contemporáneas en torno a la producción y reflexión de las Artes Visuales en el contexto escolar.

Palabras clave: enfoques de enseñanza de las Artes Visuales, Educación Artística, didáctica de las Artes Visuales.

\section{ABSTRACT}

This paper determines some frameworks for the educational teaching of visual arts in order to build a definition of artistic knowledge based upon different approaches. Some historical periods related to teaching practices have been examined. A vision from a didactic point of view of the visual arts has been built, considering some concepts and its educational implementation in school contexts. Some characteristics of the production and reflection toward the Visual Arts in the school context have been examined, considering rationalist and universalist conceptions and contemporary perspectives.

Key words: Visual Arts teaching approaches, Arts Education, Visual Arts didactics.

Este artículo presenta las reflexiones conceptuales realizadas en el contexto de los Proyectos de investigación FIBE 18-12 (2012-2013) y FIE 09-14 (2014-2015), financiados por la Dirección de Investigación de la Universidad Metropolitana de Ciencias de la Educación. 


\section{UN ACERCAMIENTO INICIAL}

Los enfoques que los profesores tienen con relación a su ejercicio profesional son profundamente significativos y determinantes, ya que nos entregan una comprensión sobre los modos en que las estrategias de enseñanza se vinculan con la producción artística. Esta orientación constituye un lugar reflexivo acerca de cómo se pueden elaborar diversos esquemas de acción y conocimiento acerca de las Artes Visuales que se dan en la escuela.

Para comprender de mejor manera cómo operan las Artes Visuales en el contexto escolar, es necesario considerar que existen diferentes modos de generar conocimiento a partir de su enseñanza y su aprendizaje. Si tomamos en cuenta que existen diversos modelos de enseñanza, consideramos que estos son una visión amplia de estrategias dadas en el quehacer docente. En palabras de Joyce y otros, un modelo "no es sino una descripción de un ambiente de aprendizaje" (Joyce, Weil \& Calhoun, 2002, p. 36). Si es cierto que un modelo de enseñanza puede tener diferentes contenidos a abordar, resulta más claro señalar que el modo en el cual estos modelos se desenvuelven se encuentra fuertemente determinado por los enfoques de enseñanza que estos mismos modelos asumen. Estos enfoques constituyen la manera específica de entender, dar a conocer y estimular el aprendizaje de las Artes Visuales desde diferentes formas de comprender sus métodos, sus tradiciones y sus formas de construcción.

Los puntos de vista acerca de la educación artística que se han dado especialmente en las últimas décadas han adquirido una mayor densidad discursiva, lo cual constituye un potencial soporte para generar acercamientos relevantes vinculados a la consistencia conceptual dada por los enfoques en la enseñanza de las Artes Visuales. Esta profundización se ha generado al tomar en cuenta el pensamiento filosófico emergente, las concepciones inter, intra y transculturales, como también al exponer problemáticas contingentes que son parte de un potencial imaginario colectivo situado en la educación, tanto en primaria como en secundaria. Por ejemplo, la condición humana y la experiencia parecen determinar nuevas interrogantes en relación con las inquietudes que pueden darse en el terreno de lo educacional (Eisner \& Day, 2004). Estos enfoques han permitido poner en tela de juicio el concepto de conocimiento totalizante esgrimido desde la modernidad, que veía en la universalidad, la racionalidad y la ubicuidad del sujeto cognoscente los mecanismos privilegiados de acceso y comprensión de lo real. Este cambio, que se da especialmente a contar del momento en que el pensamiento de lo cualitativo abre el campo de posibilidad para fenómenos más heterogéneos, repercute directamente en la producción artística. La diversidad de esta elaboración situada en la imagen permite pensar ciertos fenómenos y producir obras que se mueven en diferentes registros, explicándose a partir de ellos la complejidad de la experiencia estética contemporánea y su dificultad para ser no solo pensada, sino experimentada en el contexto escolar actual. Con ello, la educación artística que se vincula a esta misma producción también ha tenido que abordar estos conjuntos temáticos, incorporándolos como parte de su acción curricular, de sus estrategias de enseñanza y, con ello, de su comprensión acerca de las motivaciones, alcances y límites de la experiencia localizada en el espacio escolar cotidiano.

Sin embargo, la posibilidad de entrar en el pensamiento de lo complejo posee sus propios riesgos, especialmente cuando los significados abiertos no necesariamente cautelan la apropiación rigurosa de ciertos esquemas cognitivos, necesarios para el entendimiento cabal del sentido inscrito en las propuestas artísticas contemporáneas. En muchas ocasiones, 
la generación de un conocimiento artístico de baja calidad proviene de un aprendizaje deficitario (Efland, 2004), por este motivo, resulta imprescindible penetrar en el significado expansivo de los conceptos críticos que pueden ser abordados por la enseñanza de las Artes Visuales, no considerándolos como contenidos inamovibles y fijos que puedan resultar en esquemas mentales o procedimientos técnicos ingenuos o superficiales (Efland, 2004), sino en construcciones complejas, con desafíos tanto expresivos como analíticos en la comprensión de las Artes Visuales.

Por este motivo, se ha evidenciado la necesidad de levantar líneas de pensamiento en cuanto a la acción docente, los procesos cognitivos implicados que se enlacen con la experiencia de las Artes Visuales, ya sea en cuanto a su sentido, sus significados implícitos o explícitos, o bien en sus relaciones inter y transdisciplinares. Esto constituye una forma de propiciar la reflexión de los futuros profesores de Artes Visuales en cuanto a sus posibles transferencias de contenidos, sus habilidades específicas ligadas a la creación artística y, por sobre todo, su comprensión de la sensibilidad como un pensamiento que sobrepasa el análisis racional y la habilidad pensada como un manejo instrumental de la representación. Lo anterior implica un intento por lograr en los profesores la comprensión de sus propias concepciones de arte; la generación de prácticas docentes que rescaten el pensamiento complejo por sobre la identificación de componentes formales; la generación de métodos de trabajo que propongan visiones problematizadoras sobre la realidad; y la promoción de estrategias de enseñanza que permitan superar la visión de lo estético como una adecuación formal o simbólica ante el orden establecido.

El planteamiento de esta reflexión se vincula con algunas preguntas: ¿Se puede distinguir en el pensamiento didáctico que se da en la enseñanza de las Artes Visuales una diferencia sustancial en el modo de pensar la interacción entre estudiante y docente?, ¿en qué medida los diferentes enfoques de enseñanza influyen en el modo en que los docentes imparten la asignatura de Artes Visuales? Estos últimos profesionales ¿sostienen un modo de generar conocimiento o experiencia artística desde un punto de vista particular? La reflexión contenida en este texto propone tomar en cuenta diferentes enfoques de enseñanza dados en el ámbito de la educación de las Artes Visuales para, desde este conocimiento, delinear con mayor precisión estrategias de enseñanza aplicados en el contexto escolar.

\section{ENFOQUES DE ENSEÑANZA DE LAS ARTES VISUALES}

Los enfoques de enseñanza de las Artes Visuales recopilados consideran las propuestas de diferentes autores: Agirre (2005), Belver (2011), Efland, Freedman y Stuhr (2003), Eisner (2004) y Marín (1997). Ellos nos proponen diferentes planteamientos en torno al cómo enseñar desde perspectivas que toman en cuenta algunas formas del aprendizaje artístico. Por un lado, una mirada historicista, en la medida en que cada enfoque se vincula a una forma de comprensión del proceso artístico, ligada a cierto contexto cultural localizado temporalmente y que posee principios determinados por una visión sobre fenómenos estéticos particulares. Por otro lado, los estudios de estos autores analizan los acercamientos didácticos de cada enfoque en relación a sus posibilidades de influencia en la formación de los estudiantes, como sujetos conscientes de los valores culturales y sensibles que el arte ofrece para su aprendizaje. Esta mirada tiene una transferencia posible de realizar al interior del 
mundo escolar, en la medida en que considera visiones estéticas con miradas reflexivas de procesos, temáticas y fenómenos situados en ciertos contextos sociales y artísticos.

Cuadro 1. Enfoques de enseñanza de las Artes Visuales

\begin{tabular}{|c|c|}
\hline $\begin{array}{l}\text { Enfoques reconstruidos a partir } \\
\text { de modelos de enseñanza de las } \\
\text { Artes Visuales }\end{array}$ & $\begin{array}{l}\text { Modelos de enseñanza } \\
\text { de las Artes Visuales }\end{array}$ \\
\hline 1. Taller maestro aprendiz & $\begin{array}{l}\text { - Modelo del Taller del artista (Marín, 1997) } \\
\text { - Taller del artista (Belver, 2011) } \\
\text { - El arte como saber (Agirre, 2005) }\end{array}$ \\
\hline 2. Arte en la academia & $\begin{array}{l}\text { - El sistema de la academia de Bellas Artes (Marín, 1997) } \\
\text { - Las escuelas institucionalizadas de artistas (Belver, 2011) } \\
\text { - Las academias de arte (Belver, 2011) } \\
\text { - Academias de Bellas Artes (Efland et al., 2003) }\end{array}$ \\
\hline 3. Arte y diseño & $\begin{array}{l}\text { - La experimentación Bauhasiana (Marín, 1997) } \\
\text { - Resolución creativa de problemas (Eisner, 2004) } \\
\text { - Las escuelas modernas (Modelo Alemán y Ruso) } \\
\text { (Belver, 2011) } \\
\text { - Educación artística como preparación para el mundo laboral } \\
\text { (Eisner, 2004) }\end{array}$ \\
\hline $\begin{array}{l}\text { 4. Expresión y creación } \\
\text { personal }\end{array}$ & $\begin{array}{l}\text { - Desarrollo de genio y capacidad creadora (Marín, 1997) } \\
\text { - Expresión personal creativa (Eisner, 2004) } \\
\text { - El arte como expresión (Agirre, 2005) }\end{array}$ \\
\hline $\begin{array}{l}\text { 5. Desarrollo disciplinar } \\
\text { y cognitivo de las artes } \\
\text { visuales }\end{array}$ & $\begin{array}{l}\text { - Las artes y el desarrollo cognitivo (Eisner, 2004) } \\
\text { - La integración de las artes en el currículum (Eisner, 2004) } \\
\text { - Enseñanza del arte basada en las disciplinas (Eisner, 2004) } \\
\text { - La reconstrucción disciplinar de la educación artística } \\
\text { (Agirre, 2005) }\end{array}$ \\
\hline $\begin{array}{l}\text { 6. Educación artística y cultura } \\
\text { posmoderna }\end{array}$ & $\begin{array}{l}\text { - Cultura visual (Eisner, 2004) } \\
\text { - La educación artística posmoderna (Belver, 2011) } \\
\text { - El arte como sistema cultural (Agirre, 2005) } \\
\text { - El arte como experiencias estéticas contingentes } \\
\text { (Agirre, 2005) }\end{array}$ \\
\hline
\end{tabular}

En este cuadro se propone la agrupación de seis enfoques de enseñanza de las Artes Visuales y su vinculación con diferentes referentes teóricos. La clasificación de la primera columna se ha hecho tomando en cuenta los aportes de autores que han sistematizado, de una u otra manera, ciertos modos de impartir la asignatura, dependiendo de cómo se consideran los productos artísticos, qué métodos de trabajo estos mismos enfoques privilegian y las formas de utilizar ciertos conceptos artísticos y de aprendizaje. Todos los enfoques poseen una manera particular de concebir cómo los estudiantes desarrollan 
su aprendizaje, por lo que existe una clara relación entre arte, aprendizaje y enseñanza. En la segunda columna se presentan los referentes teóricos que, en su conjunto y desde la educación artística, permiten desarrollar una mayor densidad descriptiva de cada uno de los enfoques. La reconstrucción de estos enfoques tiene por objetivo sistematizar su comprensión de un modo que incluye aspectos históricos y metodológicos que se dan al interior de cada uno de estos. A continuación se desarrolla su caracterización.

\subsection{ENFOQUE 1: TALLER MAESTRO-APRENDIZ}

La concepción fundamental de este enfoque toma en cuenta las habilidades y conocimientos determinados por una tradición, la que se transmite desde la visión de un artista altamente competente en lo técnico, sensible y creativo. El taller maestro-aprendiz se encuentra determinado, en gran medida, por las condiciones culturales producidas a partir de la conciencia autoral de las obras, específicamente a partir del Renacimiento y los posteriores estilos que se desarrollan durante la época moderna.

Este enfoque considera las conceptualizaciones del Taller del artista de Marín (1997), Taller del artista de Belver (2011) y la definición de Arte como saber de Agirre (2005). Todos estos modelos poseen como denominador común el pensar en una cierta pureza de la obra de arte, que se liga directamente con el talento del artista creador quien, al establecer un permanente contacto hacia un aprendiz, posibilita la generación de habilidades destinadas a obtener un producto artístico que se liga a un bien hacer desde el punto de vista de la creación plástica.

El foco de enseñanza se dirige a lograr que los estudiantes generen una sensibilidad que explore desde su propia percepción de lo original y sensible, aquellos aspectos técnicos que se dan en diferentes medios de producción artístico visual. Por otra parte, se pretende propiciar una identificación clara acerca de los contextos históricos y culturales que rodean la obra de arte, entendida como una culminación de habilidades propias de la sensibilidad de este artista. También se persigue justificar las afirmaciones en cuanto a las funciones y sentidos del arte, su relación con el formalismo y el manejo instrumental de las técnicas utilizadas. Como es de esperarse, estas técnicas se eligen tomando en cuenta su inscripción dentro de una tradición específica, que veía en las posibilidades plásticas del manejo de ciertos materiales nobles el campo propicio para el desenvolvimiento competente y sensible de parte de una visión y acción privilegiados por una excelencia técnica. La transmisión del saber se realiza por medio de la imitación y la repetición de esquemas dados en la producción artística, y que exploran en la percepción una suerte de mirada isométrica entre realidad y representación. La progresión de aprendizajes se funda en la adquisición de habilidades y en la autoridad del maestro-artista, quien ve en el cultivo de estas aptitudes la posibilidad de desarrollar un oficio al que se dedicará en el futuro, en ocasiones con un fuerte componente vocacional.

En el aprendizaje escolar se puede detectar una visión inductiva, donde el docente guía el proceso de aprendizaje, aplicando habilidades técnicas del oficio artístico, intentando obtener aquello que cumple con una expectativa normada por una tradición artística externa al estudiante, y que valida la ejecución del trabajo artístico mediante la obtención de ciertos estándares. En este caso, la experiencia de lo estético se relaciona fuertemente con una apreciación de los aspectos formales de la imagen como una forma de acceder a un bien hacer en función de una sensibilidad artística que sobrepasa la sensibilidad cotidiana. 


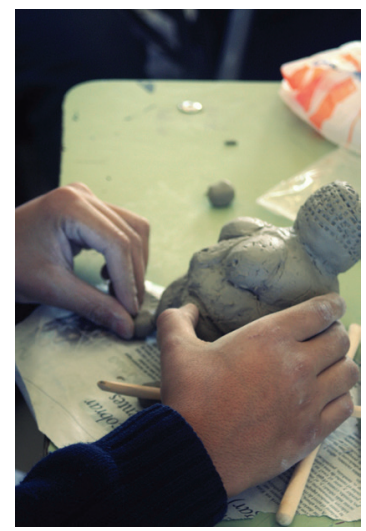

Por otra parte, el docente asume un rol de modelador que potencia el que los estudiantes reproduzcan estrategias técnicas y procedimientos, cumpliendo una suerte de papel de "maestro" de la producción artística. En este rol, es necesario ofrecer retro-alimentaciones constantes al evaluar las actuaciones de los aprendices, las decisiones en torno a la producción de obra y las concepciones erróneas que se lleven a cabo en el transcurso del proceso de enseñanza y aprendizaje.

Se puede afirmar que el objetivo fundamental de este enfoque es rescatar una experiencia estética que se posiciona en tanto reflejo del quehacer "adecuado" de un artista que establece una manera virtuosa de generar la representación como "imagen del mundo". La vivencia o experiencia que este enfoque potencia es, quizás, restrictiva en el sentido de que la representación "retiniana" de la realidad es el punto de referencia esencial del quehacer artístico. Sin embargo, se trata también de la articulación de una experiencia estética, que se da en la medida en que el o la estudiante imita la manera de desarrollar una obra artística de acuerdo a la mediación de un maestro.

\subsection{ENFOQUE 2: ARTE EN LA ACADEMIA}

La principal visión de este enfoque considera las convenciones de la institucionalidad artística dada en el contexto europeo, específicamente con el surgimiento de la Academia de Bellas Artes, en donde el seguimiento de una forma canónica de representación se inscribe en un "bien hacer", determinado por una fuerte construcción situada en la óptica formal. Arte en la Academia se constituye principalmente como una muestra de la racionalidad ilustrada, que se incorpora a las formas de representación visual promoviendo estrictas leyes formales que determinan la noción de belleza.

Fotografía del trabajo de un/a estudiante de 12 años, tomada en la práctica profesional realizada en el año 2013 por la profesora en formación Vanessa Oliveros del Departamento de Artes de la Universidad Metropolitana de Ciencias de la Educación. En la medida en que el trabajo artístico se encuentra ligado a una tradición cultural que se ha posicionado como hegemónica, sus prácticas se encuentran determinadas en gran medida por un seguimiento de esa tradición. 
Este enfoque surge de la relación entre el sistema de la Academia de Bellas Artes planteado por Marín (1997), el modelo de las Escuelas institucionalizadas de artistas y de las Academias de arte propuesto por Belver (2011) y las Academias de Bellas Artes presente en Efland et al. (2003). Estas referencias se contextualizan en el período histórico del siglo XVII, bajo el bastión metafórico de la Edad de la Razón Ilustrada. En este contexto, el pensamiento científico comienza a establecer vinculaciones con el absolutismo político y posteriormente con el parlamentarismo. Se considera al arte como un medio efectivo para promover el retorno a atributos de la imagen determinados por la valoración de los aspectos formales, racionalizados y fuertemente ligados a la representación óptica. Esta preferencia por los aspectos formales intensamente subrayados por la percepción visual establecen, de hecho, una configuración de lo óptico como un componente fundamental del régimen escópico moderno (Jay, 2007).

Con respecto a los inicios de la Academia de Bellas Artes, Efland et al. (2003) señalan que "la Academia estaba encargada de transmitir los principios del arte a sus miembros por medio de conferencias y lecciones impartidas a los estudiantes a través de dibujos tomados del natural" (p. 64). Se otorgaba una gran importancia a los contenidos sobre perspectiva, geometría, anatomía y al análisis de pinturas desde la óptica de categorías tales como la invención, la proporción, el color, la expresión y la composición. Esta progresión curricular constituye la esencia del método academicista de la enseñanza de las artes desde finales del siglo XVII hasta finales del siglo XIX. En cierto modo, se trata de un enfoque que va más allá de los aspectos sensibles del artista individual, para consolidar un conocimiento compartido en torno a una exactitud técnica, fidelidad al modelo y adecuación a normas formales fundadas en aspectos visuales. Por lo tanto, las academias de arte instruyen artistas para que sean capaces de instalar, por medio de conocimientos disciplinares heredados del Renacimiento, obras visuales que enaltecen por su grado de factura mimética y técnica que comienza a desarrollarse principalmente en Europa.

Este modelo considera estrategias de enseñanza que permiten la adquisición de conocimientos disciplinares validados a través de un método muy normado, coherente con la racionalidad instrumental, que se encarga de manipular controladamente la representación de las imágenes fundadas en la realidad. Estos conocimientos serán aplicados en la elaboración de obras visuales realizadas mediante el dibujo, la pintura, la escultura, herencia, en parte, de la tradición precedente ligada a la "nobleza" de los materiales. Dentro de esta metodología de enseñanza es necesario que los contenidos sean ordenados de forma secuencial, procurando sistematicidad en su progresión, ya que cada conocimiento o saber se ubica como pre-requisito de otro, en el marco de una programación delimitada. En el contexto escolar, este modelo requiere que el estudiante memorice diversos conocimientos disciplinares tanto por definición como por asociación. Esto último debido al necesario ejercicio del reconocimiento de espacios u objetos concretos, los cuales actúan como referentes visuales de las obras que los estudiantes desarrollarán. Por ejemplo, ante la comprensión conceptual de la simetría, es necesario que el estudiante reconozca esta propiedad en la configuración de los elementos que observa de su entorno. El enfoque de Arte en la academia, basado en anclajes y asociaciones, posee una fuerte conexión con la repetición de procedimientos, la memorización de algunos conceptos claves para su aplicación y representa una forma de generar conocimiento y experiencia, tomando en cuenta elementos fundamentales para la perspectiva clásica del arte. 


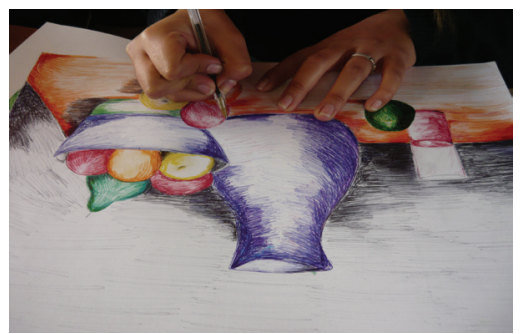

En el aula se utiliza una programación sistemática de los conocimientos artísticos que pretende el logro de resultados formales previamente aceptados por una comunidad académica que los valida. Se espera que la obra visual ejecutada evidencie un resultado preestablecido, por sobre la necesidad expresiva personal del creador, bajo una continua supervisión por parte del docente. Ante este enfoque, la experiencia estética posee ciertos rasgos que pueden ser ligados a una predominancia de la racionalidad, tanto instrumental como conceptual, dirigida a explorar los fenómenos sensibles en tanto estímulos perceptuales situados en la visión más concreta y menos interpretativa.

Las características de la experiencia estética en este contexto consideran ciertas operaciones de mirar el mundo y sus aspectos formales, otorgándoles un valor nominal, lo cual constituye una entrada a la comprensión de la propia sensación como una experiencia inscrita en el marco de la percepción inmediata y la racionalización de esta visión.

Las posibilidades y límites que posee este enfoque consideran, principalmente, el hecho de construir un conocimiento con sus reglas, lenguaje, sistemas de trabajo, que genera expansiones a otras áreas cognitivas, tales como la geometría dada en las formas que buscan la armonía formal, la anatomía de las formas vivientes y los conceptos que denominan fenómenos dados en la visualidad. Las limitantes se producen desde el momento en que este enfoque subraya el peso de la ley formal por sobre los fenómenos sensibles del ejecutor, en este último sentido, la tradición del quehacer puede generar un peso que restrinja las posibilidades de expresión creativa.

\subsection{MODELO 3: ARTE Y DISEÑO}

El principal componente de este enfoque es la relación entre la producción artística y las aplicaciones del diseño como disciplina independiente que enfatiza la solución de problemas dados en el ámbito visual y funcional.

En la conceptualización de este enfoque se ha tomado en cuenta la Experimentación bauhausiana de Marín (1997), la Resolución creativa de problemas, la Educación artística como preparación para el mundo laboral de Eisner (2004), como también las Escuelas modernas (modelo Alemán Bauhaus y Ruso) planteadas por Belver (2011). Estos enfoques nacen en el contexto post Revolución industrial, en donde se concibe el arte

Fotografía del trabajo de un/a estudiante de 14 años, tomada en la práctica profesional realizada en el año 2013 por la profesora en formación Jazmine Guerra del Departamento de Artes de la Universidad Metropolitana de Ciencias de la Educación. Al considerar el naturalismo como un referente, se opta por la aplicación de componentes técnicos en la construcción de la obra visual. 
desde una mirada focalizada en la producción en serie. Su objetivo es la formación de trabajadores que diseñen nuevos productos con una función utilitaria o respondiendo a tendencias políticas de la época, y en donde la identidad del artista creador va perdiendo fuerza (Belver, 2011).

En Alemania, su manifestación máxima es la Bauhaus, que combina e integra las Bellas Artes y el diseño, este último aplicado principalmente a la industria. Su objetivo principal era abordar problemas de trascendencia social con métodos técnicamente eficaces y una estética satisfactoria (Eisner, 2004). Para la Bauhaus la formación de los artistas se basó en principios arquitectónicos, escultóricos y pictóricos con una fuerte mirada sobre la funcionalidad y el diseño, de tal manera que la labor del artista se fusionó con la del artesano. En el caso de la Unión Soviética (Belver, 2011) se desarrolla una mirada similar, integrando lo artístico con lo social al unir las academias de Bellas Artes con las escuelas de artes y oficios. En este contexto se realizaron reformas pedagógicas que tuvieron como eje la creación artística basada en la ciencia y la técnica, ambas con un poderoso impulso hacia el mejoramiento de la vida cotidiana de la sociedad.

Este enfoque considera que las Artes Visuales son esencialmente un lenguaje, cuyo vocabulario, y por lo tanto su forma de desarrollar conocimiento artístico, está compuesto por elementos gráficos abstractos fundamentales como punto, línea, plano, textura y color. El dibujo, la pintura y la escultura ya no tienen que estar focalizados en imitar la realidad, sino que más bien pueden concentrarse en su propia realidad expresiva como elementos autónomos. El enfoque de Arte y Diseño potencia un sentido de la imagen a través del estudio de formas, líneas, texturas y colores con un fuerte acento en la funcionalidad de los objetos y la claridad comunicativa de las imágenes.

En el contexto de la escolarización formal, su estrategia es la solución de problemas concretos (Eisner, 2004), considerando una suma de elementos en la toma de decisiones, como el carácter económico, estructural, ergonométrico y estético de sus producciones. La cooperación entre pares en el aprendizaje resulta fundamental, debido a que la resolución de problemas visuales y funcionales requiere de un ejercicio cooperativo entre los estudiantes durante actividades de índole práctica. Esta interacción favorece la adquisición de información y el desarrollo de habilidades destinadas a resultados cuyo logro es evidente para el conjunto de personas insertas en el proceso. Se requiere, por parte del profesor, la presentación de un problema o concepto estimulante en la generación de un proceso artístico y/o visual. Ante dicha situación, los estudiantes desarrollan intentos de resolución de problemas y se organizan con el fin de descubrir su naturaleza, plantear soluciones, revisar la información que se posee para resolverlos, expresar sus ideas durante el proceso de resolución, para finalmente aplicar las conclusiones obtenidas. 


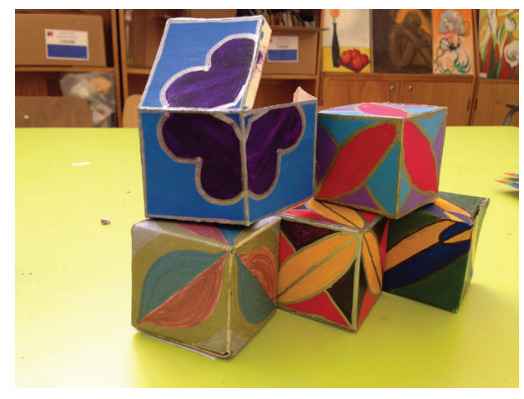

La principal fortaleza de este enfoque es su potencial aplicabilidad en función de necesidades específicas, tales como la coherencia entre mensaje y forma, la solución de un problema visual o funcional en relación a una armonía o equilibrio, como también el reconocimiento de innovaciones que satisfagan las necesidades cotidianas. Sus límites probablemente apuntan al énfasis que se le dé a la funcionalidad comunicativa u operacional, que pueden condicionar el desarrollo de habilidades que pueden dejar fuera el desarrollo de habilidades con predominancia en lo expresivo.

\subsection{ENFOQUE 4: EXPRESIÓN Y CREACIÓN PERSONAL}

El componente principal de este enfoque tiene relación directa con la noción de creatividad, más allá de la discusión que se puede establecer al momento de definir este concepto. Se puede entender que la creatividad se piensa aquí como una forma individualizada de generar imágenes con diferentes sentidos.

Este modelo recoge los conceptos ligados a la Expresión personal creativa (Eisner, 2004), el Desarrollo del genio y la capacidad creadora (Marín, 1997) y el Arte como expresión (Agirre, 2005). Un aspecto común a todos estos enfoques es que reflexionan sobre cómo se genera la expresión de impulsos personales, estimulando el proceso de la producción creativa, prescindiendo de directrices que se desprendan de la formación tradicional o de estructuras formales de enseñanza y aprendizaje artístico.

Diferentes movimientos artístico visuales, que se desarrollaron en el contexto de los conflictos bélicos de la primera mitad del siglo XX, tomaron distancia del dominio de la técnica y la racionalidad presentes en el arte. Estas manifestaciones, agrupadas bajo la noción de vanguardias, consideraron que dichos fundamentos son un reflejo de la sociedad que atenta contra sí misma por medio de sus avances tecnológicos y estructuras inhumanizantes. Tal extremo genera una contraparte, la expresión espontánea, sensible e individualizada, negada o menospreciada por la hegemonía de la racionalidad precedente.

\footnotetext{
Fotografía del trabajo de un/a estudiante de 13 años, tomada en la práctica profesional realizada en el año 2013 por la profesora en formación Evelyn Solís del Departamento de Artes de la Universidad Metropolitana de Ciencias de la Educación. Se considera en el planteamiento de esta actividad que observamos un trabajo de diseño de módulos, el cual permite desarrollar en sus estudiantes la solución de problemas que considera principios como la armonía y el equilibrio en la composición de las formas, para la obtención de un resultado que responda a una necesidad concreta.
} 
Dentro del ámbito educacional, la presencia del imaginario artístico visual adquiere gran importancia, constituyéndose como estímulo en la generación de nuevos movimientos expresionistas y reconstruccionistas de la Segunda Guerra Mundial en Europa y Estados Unidos. Se comienza a considerar las reproducciones visuales infantiles, así como también la concepción teórica que plantea la importancia del arte como medio para el desarrollo de la creatividad, promovida por Lowenfeld y Brittain en la década del 50. Estos nuevos referentes incitan al desarrollo de una educación artística que se distancie de los marcos y normas disciplinares de las Bellas Artes establecidos en la Academia, para otorgar licencia a la expresión espontánea, donde la imaginación es equivalente a la creatividad vista como la individualidad que se expresa a sí misma.

El desplazamiento de este modelo al ámbito de las estrategias pedagógicas exige que el estudiante se conecte con su sensibilidad, constituyendo experiencias estéticas capaces de estimular y generar nuevos procesos creativos personales, donde el docente solamente cumpla una función de acompañante de las diferentes soluciones visuales que el estudiante va generando a partir de sus intereses y motivaciones. Un aspecto llamativo es que la evaluación está determinada por los propios desafíos que el estudiante se proponga, pero, en ningún caso, por los conocimientos disciplinares que el docente espera que el estudiante alcance.

Figura $4^{4}$

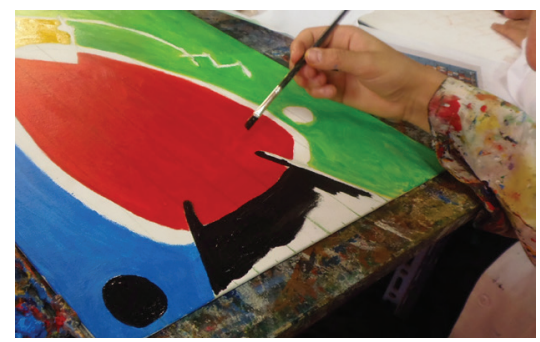

Este enfoque permite al estudiante expresar su interioridad emocional procurando, además, resolver o, al menos, dialogar con sus preocupaciones. Para tales efectos, el estudiante plantea sus emociones y preocupaciones para luego definirlas; el docente genera preguntas y/o situaciones para contribuir a la verbalización y formalización de los sentimientos individuales; luego, el estudiante determina visualmente, a través de distintos medios, sus sentimientos y emociones, favoreciendo una riqueza interpretativa de su sentir. Probablemente sea este enfoque el que más se ajusta a un imaginario colectivo que concibe la percepción subjetiva, la experimentación con el material, la imaginación individual y el procedimiento talentoso como medios de entrada a la creación sensible. La experiencia estética se sustenta en gran parte sobre las decisiones del sujeto, quien explora en las

Fotografía del trabajo de un/a estudiante de 12 años, tomada en la práctica profesional realizada en el año 2013 por la profesora en formación Camila Borgna del Departamento de Artes de la Universidad Metropolitana de Ciencias de la Educación. Esta pintura refleja la expresión y emoción de la estudiante, por medio de recursos pictóricos. Se recurre a cierta flexibilidad en su uso para poder representar aspectos subjetivos. 
posibilidades visuales que le otorgan tanto la configuración potencial que posee el material elegido, como sus propias indagaciones en torno a su intuición, memoria e imaginación.

Las potenciales ventajas de este enfoque son la conciencia que se produce en el proceso de producción de imágenes acerca de la propia sensibilidad, la atención hacia áreas o disciplinas de conocimiento que pueden detonar procesos de creación no contemplados por métodos tradicionales y la conciencia acerca de la búsqueda de la innovación como valor artístico. La principal desventaja es que a partir de la concepción de "autoexpresión", si esta no está completamente clara, es posible que la producción e interpretación de productos artísticos sea excesivamente relativizada y subjetiva.

\subsection{ENFOQUE 5: DESARROLLO DISCIPLINAR Y COGNITIVO DE LAS ARTES VISUALES}

La cognición resulta ser un punto focal de atención para determinar en qué medida las Artes Visuales aportan en el desarrollo integral de los sujetos. Gran parte del trabajo de investigadores en relación al área educacional se ha servido de algunas descripciones dadas en el ámbito psicológico para poder establecer algunos puntos que permitan operar en la comprensión del fenómeno del aprendizaje desde las Artes Visuales. Este análisis de las condiciones en que se produce el aprendizaje también considera que el modo de construir conocimiento varía dependiendo del enfoque disciplinar.

Se considera para la argumentación de este enfoque, la relación entre las Artes Visuales y el desarrollo de formas específicas de pensamiento por una parte, por otra los vínculos entre la disciplina artística y otras áreas de conocimiento. Las ideas que sirven de referencias para articular la concepción de este enfoque son las relaciones que Eisner (2004) establece entre las artes y el desarrollo cognitivo, la integración de las artes en el currículum y la enseñanza del arte basada en las disciplinas (DBAE). Por otro lado, resulta importante destacar la Reconstrucción disciplinar de la educación artística de Agirre (2005).

En cuanto a las implicancias educacionales, desde algunos sectores se argumenta que las artes tienen poco que ver con formas más avanzadas de cognición. Ello se da especialmente cuando en el discurso se habla de ciertas habilidades duras y blandas, dando a entender, dentro del lenguaje, una visión que promueve una cierta jerarquización de la complejidad, como si las formas objetivas de la construcción del conocimiento tuvieran una racionalidad de mayor grado que la interpretación o creación a partir de estímulos sensoriales mediatos o inmediatos. Este sesgo obedece a una simplificación que vincula a las Artes Visuales únicamente con los sentimientos y los elementos técnicos inscritos en la producción visual, como si el pensamiento racional fuese patrimonio exclusivo de las así llamadas ciencias duras. El enfoque descrito propone integrar las artes visuales a otras materias y se suele organizar en función de cuatro acciones concretas. En primer lugar, la comprensión de un periodo histórico concreto o una cultura determinada, tomando en cuenta su producción cultural y artística. En segundo término, los estudiantes identifican las similitudes y diferencias entre las distintas formas de expresión artística visual. En tercer lugar, la exploración e identificación de una idea fundamental que se investiga a partir de obras de arte, considerando temas de diversa naturaleza. Por último, la resolución de ciertos desafíos específicos para que los estudiantes puedan abordar diferentes disciplinas, incluyendo las artes (Eisner, 2004). 


\section{Figura $5^{5}$}

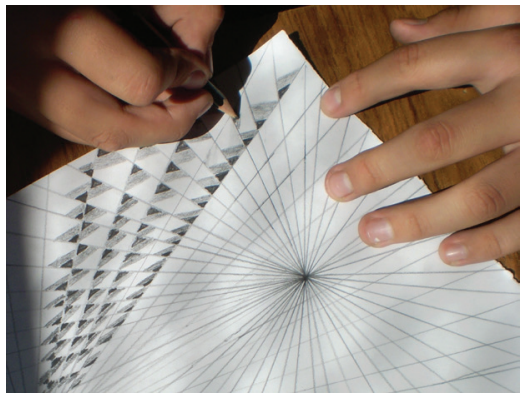

Dentro del aprendizaje escolar, el arte puede generar modos complejos del pensamiento. Por ejemplo, cuando se le pide a los estudiantes que formalicen, a través de sus propios conceptos, los objetivos en relación a la forma artística que desean generar. Esta acción los invita a constituir dentro del lenguaje las expectativas que los mueven y que se traducen en el marco de la representación visual personal o colectiva. La contemplación de los aspectos visuales a través de la percepción sensorial, como también de la reflexión que se genera a partir de esta visión permitiría a los estudiantes establecer una perspectiva meta-cognitiva de sus procesos expresivos. Ello en la medida en que puedan identificar, con la mediación de diversas estrategias del docente, los puntos en que se apoya su propuesta de trabajo artístico. El uso de las artes para mejorar el rendimiento establece que en la medida en que se realicen actividades de artes, mejorará su rendimiento escolar en otras áreas, aunque se deban tener aún algunas explicaciones alternativas a este fenómeno (Vaughn \& Winner, 2000).

Dentro de este marco ¿se podría pensar en las Artes Visuales como una cognición compleja en función de sus líneas de producción ligadas a diferentes ámbitos de conocimiento? La investigación actual parece estar dando algunas luces al respecto. Quizás podríamos afirmar que la producción visual de los estudiantes puede representar, ante ellos mismos, una conexión verificable tanto a través de la percepción de la imagen como por medio de una identificación explícita dada en el lenguaje de los vínculos de la representación artística con otras áreas del currículum. Sería esta posibilidad, la de ejecutar una transferencia de lo cognitivo en diferentes ámbitos del conocer, lo que potenciaría la certeza de que las artes visuales permiten incrementar la calidad de los aprendizajes. Sin embargo, también queda la inquietud acerca de hasta qué punto el considerar a las artes visuales como complemento del currículum puede influir en su especificidad.

\subsection{ENFOQUE 6: EDUCACIÓN ARTÍSTICA POSMODERNA}

Este enfoque se desarrolla especialmente a partir de la reconsideración del relato de progreso establecido por la Modernidad. El replanteamiento de los límites del enfoque moderno

Fotografía del trabajo de un/a estudiante de 15 años, tomada en la práctica profesional realizada en el año 2013 por la profesora en formación Paulina Ramírez del Departamento de Artes de la Universidad Metropolitana de Ciencias de la Educación. En esta imagen se puede observar conocimiento de otras áreas, por ejemplo la geometría pueden aplicarse para obtener resultados visuales que recojan valores de la expresión visual en concordancia con componentes relacionados con la lógica geométrica. 
trae consigo la incertidumbre acerca de los significados que, en última instancia, el estructuralismo trató de articular como sistema de univocidad semántica de la modernidad tardía (Agirre, 2005). Para ello, el sistema cultural posmoderno propone situarse en posiciones críticas que toman en cuenta las identidades, temas y situaciones de vida de las minorías raciales, sexuales y de género. Para ello se hace necesario incluir concepciones que tomen en cuenta la diferencia y la alteridad como estrategias del desarrollo expresivo (teorías multiculturales, concepciones feministas, etc.) (Acaso et al., 2011).

Este enfoque se basa en las descripciones de tres autores: la Cultura visual de Eisner (2004), la Educación artística posmoderna de Belver (2011), el Arte como sistema cultural y el Arte como experiencia estética contingente de Agirre (2005). Cabe destacar que el modelo de Belver posee una importante base argumentativa en el enfoque de Efland et al. (2003). Los planteamientos propuestos por estos autores coinciden en la importancia de la posición crítica hacia las manifestaciones de la cultura visual contemporánea, entendiendo como tal la producción de imágenes en diferentes formatos, medios y contextos, estableciendo tanto funciones como sentidos múltiples y polisémicos.

Especialmente, a contar de los años setenta, la noción de posmodernidad se genera como una forma de revisión crítica de los lineamientos de la visión ilustrada, particularmente la noción de progreso (Efland et al., 2003). Esta visión representa por sí misma una categoría que es difícilmente reductible. Sobre todo si consideramos a la posmodernidad como un enfoque que permeabiliza las fronteras epistemológicas. Es debido a este replanteamiento que el debate actual acerca de cómo pensar la relación entre arte y visualidad se ha hecho más dificultoso. La incorporación del análisis de los procesos de creación en la producción visual artística actual permite delimitar con mayor precisión el sentido que la experiencia estética puede tener en el escenario educativo.

La estrategia de enseñanza de este modelo posee una particular complejidad, ya que el conocimiento y la práctica generados bajo su alero se enfocan justamente en cuestionar las categorías, tradiciones, enfoques, temáticas y concepciones epistemológicas presentes a lo largo de la modernidad. El tema de la educación artística actual da paso a métodos que consideren un mayor pluralismo cultural para alejarse de los métodos modernos de la enseñanza del arte. Esto incluye la aparición de los discursos no solo de los expertos y docentes, sino también de los mismos estudiantes (Hardy, 2010). Al momento de construir un currículum que esté sustentado en la posmodernidad se debe considerar que el arte constituye una producción cultural; que los relatos de varias personas o grupos marginados apoyan la idea de que las obras de arte tienen múltiples codificaciones; que el valor de mejorar y profundizar nuestro entendimiento del panorama social y cultural es una misión de las artes (Efland et al., 2003).

En términos didácticos, la aplicación de este enfoque puede darse en la medida en que los docentes promuevan una exploración de las implicancias interpretativas y productivas que se den en el trabajo de aula de sus estudiantes. La interpretación que los estudiantes puedan ejercer sobre diferentes temáticas coherentes con el mundo que les rodea es fundamental para desarrollar posiciones de análisis personal y reflexivo sobre temas relevantes para sus vidas. No se trata de desarrollar conciencia sobre las problemáticas personales con un enfoque terapéutico, sino de encontrar un sentido social y cultural (Freedman, 2006, p. 190). Por otra parte, el campo de producción artística, dado dentro del espacio escolar en términos de su experimentación material y técnica, es un punto de igual importancia para promover una mirada que sobrepase las categorías tradicionales en cuanto a sus enfoques técnicos. 
Figura $6^{6}$

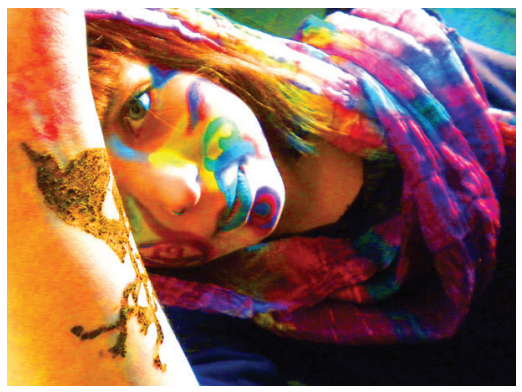

La concepción de posmodernidad es una visión que puede considerarse problemática, pues no se trata de un término que haya sido aceptado en su totalidad. De hecho, existen autores que han descartado pensar en lo posmoderno como una categoría en la medida en que conciben la época actual "como un súper-desarrollo de lo moderno" (Osborne, 2010, p. 153). Aun así, si persistiéramos en esta denominación, la denegación de lo moderno en el contexto contemporáneo se aprecia como uno de los puntos más sobresalientes de esta concepción. Si pudiésemos subsumir el enfoque de educación artística en la posmodernidad bajo esta visión, quizás podríamos afirmar que la sensibilidad estética situada en el contexto escolar se articularía como una fuerza de oposición a la normativa. Una conciencia en torno a las formas de denegación de lo posmoderno que se traducirían en la producción visual como un conjunto articulado de oposiciones a diferentes formas de comunicación, expresión, transmisión de valores y simbolizaciones de las formas precedentes de producción de obras artísticas.

\section{A MODO DE CONCLUSIÓN}

Hemos revisado seis enfoques de Educación Artística visual intentando distinguir algunos de sus atributos didácticos, en el entendido de ligarlos a la producción artística que se genera en la escuela. Esta sensibilidad, conectada a fenómenos representados en la imagen, puede considerarse como parte de una experiencia estética, en el sentido de representar un juicio de valoración, de crítica y reflexión acerca de las imágenes generadas en el marco de la experiencia artística personal o colectiva.

Actualmente, nos hemos acostumbrado a un mundo en donde se producen cambios con una velocidad sin precedentes. Ello nos obliga a cuestionar la noción de nuestro conocimiento en sus diversas esferas. La teoría desarrollada desde la objetividad de lo cuantitativo y, por otra parte, del pensamiento científico basado en las ciencias naturales, ha incorporado otros puntos de referencia, que construyen un pensamiento crítico en base a fenómenos que incluyen el concepto de interpretación. Se trata de una ampliación

Fotografía del trabajo de un/a estudiante de 15 años, tomada en la práctica profesional realizada en el año 2013 de la profesora en formación Claudia Godoy del Departamento de Artes de la Universidad Metropolitana de Ciencias de la Educación. En este trabajo se tensiona la propuesta artística de la estudiante y su cuerpo, ya que se tensiona el concepto de lo pictórico poniendo al cuerpo como un nuevo soporte de inscripción visual. 
del paradigma cognitivista, que posiciona a la subjetividad en un sitio más relevante. El conocimiento que se construye a partir de la experiencia y el pensamiento de las Artes Visuales se va configurando desde lo interpretativo y la praxis. Esta expansión se encuentra inspirada en gran medida por las posibles lecturas de la producción artística basadas en la interpretación hermenéutica (Borgdorff, 2010). Es esta misma interpretación la que nos permite entrar a un pensamiento acerca del fenómeno estético como un acontecimiento que no se encuentra aislado ni restringido a formas sensibles no condicionadas por la racionalidad. Se trata más bien de considerar la enseñanza de las artes visuales como un conjunto de fenómenos que pueden ser experimentados desde diferentes enfoques de pensamiento y acción. Son estos enfoques los que permiten concebir el fenómeno artístico actual como disposiciones complejas de pensamiento y sensibilidad.

Este tipo de problemáticas alude a una necesidad: la de enfrentar la realidad del mundo contemporáneo con claridad en relación a los supuestos epistemológicos que constituyen el marco de referencia de la acción docente. La superación de las formas binarias de oposición entre conceptos ha dado paso a una deconstrucción que pone énfasis en la identificación de estas oposiciones, pero al mismo tiempo pretende señalar de qué manera sus componentes no son excluyentes, sino que conforman una articulación que permite comprender su complejidad (Addison \& Burgess, 2007).

Para finalizar, Eisner (2004) propone algunos principios que se deben considerar en la educación artística y, con ello, lo que podemos denominar como experiencia artística. El primer principio está en relación con el objetivo primordial de la educación artística visual, esto es "colocar en un primer plano lo que las artes tienen de distinto" (p. 65), lo cual quiere decir que no se deben buscar justificaciones del para qué existen las artes, sino valorarlas por lo que poseen de distinto a las otras disciplinas y por su valor intrínseco, el cual permite hacer visible aspectos del mundo con recursos plásticos y visuales, mostrando a los estudiantes el carácter significativo que posee el arte en sí.

El segundo principio está en relación con la inteligencia artística, la cual debe ser fomentada a partir de la reflexión que se da como una condición fundamental para la creación, "los enseñantes de arte ayudan o deberían ayudar a sus estudiantes a ser más inteligentes en relación con el arte en todas sus manifestaciones, incluyendo la cultura popular" (Eisner, 2004, p. 66). Estos logros que entrega la cognición en torno a las artes y su desenvolvimiento histórico, técnico y cultural son potenciales herramientas que guiarían el esclarecimiento de los atributos estéticos de las obras producidas, entendiendo como dichos atributos las características visuales que demuestran sustentarse en elementos cognitivos extra-artísticos.

El tercer principio está en relación con la visualidad, "la educación artística debería ayudar a los estudiantes a aprender a crear y a experimentar las características estéticas de las imágenes y a comprender su relación con la cultura de la que forman parte" (Eisner, 2004, p. 67). Los programas escolares deberían considerar una concepción de lo visual de manera integrada y así tener una mirada sobre lo estético que considere las diferentes formas visuales que están en la cultura.

El cuarto principio está en relación con los propios estudiantes: las artes se convierten en una oportunidad para que sean conscientes de su propia individualidad, pueden contribuir a la creación de una visión personal a partir del desarrollo de la observación de sutilezas de las propias obras. La experiencia estética se daría, en este contexto, en la medida en que lo sensible se vincula directamente consigo mismo. 
El quinto principio afirma que los programas de educación artística deben procurar que los estudiantes tengan experiencias estéticas a partir de la vida cotidiana. Su objetivo es rescatar, desde el mundo general que poseen los estudiantes, el potencial de deleite y fuente de significado. Considera que la escuela puede ofrecer un marco para contemplar el mundo con conceptos mucho más amplios y diversos.

Cada uno de los seis enfoques recopilados conlleva una mirada teórica potencialmente aplicable al mundo educativo y, dentro de esa mirada, una postura de lo que se espera en la formación artística visual de niños y jóvenes. Lo que este texto desea enfatizar es la inexistencia de un enfoque predominante con respecto a otro: lo fundamental es considerar su aplicación en el aula, a partir de su coherencia con los objetivos y contenidos que se persiguen, las características de los estudiantes que accederán a la educación artística visual y las subsecuentes concepciones del fenómeno estético que se da a partir de las acciones realizadas en el aula.

Un profesor/a flexible y consciente de los diferentes aprendizajes que se dan en la producción artística en la escuela sabrá movilizarse y transitar entre los diferentes enfoques de enseñanza de las artes visuales, para así generar una comprensión profunda de las artes y sus posibilidades expresivas, críticas y analíticas. Se trata de posicionarse, primero, como un facilitador de ciertos contenidos, emanados desde un modelo curricular que prescribe lo que los estudiantes deben aprender. En segundo término, se trata también de que el o la docente pueda des-localizarse respecto de sus propias inclinaciones metodológicas, de sus sesgos en relación a lo que considera como una experiencia válida para producciones artísticas particulares y de que, en definitiva, sea capaz de comprender qué significa enseñar las Artes Visuales dentro de las problemáticas actuales. Quizás es saber que en el tránsito desde un enfoque a otro se juega un marco de referencia que otorga propósitos, comprensión y sentido a la obra de arte, que a su vez representa a toda una diversidad cultural en que están inmersos los estudiantes a fin de dar a la educación el enfoque, la metodología y las didácticas más apropiadas a los contextos, necesidades y posibilidades de transformación que el arte puede aportar desde una perspectiva formativa y transformadora de la experiencia individual, social, escolar y comunitaria. (Jiménez, Aguirre \& Pimentel, 2009, p. 13).

\section{REFERENCIAS BIBLIOGRÁFICAS}

Acaso, M., Belver, M., Nuere, S., Moreno, M.C., Antúnez, N., \& Ávila, N. (2011). Didáctica de las Artes y la cultura visual. Madrid: Akal.

Addison, N., \& Burgess, L. (2007). Learning to Teach Art and design in the Secondary School (2nd. ed.). London: Routledge.

Agirre, I. (2005). Teorías y prácticas en educación artística. Barcelona: Octaedro.

Belver, M. (2011). Artistas y modelos de enseñanza. En M. Acaso, M. Belver, S. Nuere, M.C. Moreno, N. Antúnez y N. Ávila, Didáctica de las Artes y la cultura visual (pp. 13-34). Madrid: Akal.

Borgdorff, H. (2010). The Production of Knowledge in Artistic Research. In M. Biggs \& H. Karlsson, The Routledge Companion to Research in the Arts (pp. 44-63). London: Routledge.

Efland, A. (2004). Arte y cognición. La integración de las Artes Visuales en el currículum. Barcelona: Octaedro.

Efland, A., Freedman, K., \& Stuhr, P. (2003). La educación en el arte posmoderno. Barcelona: Paidós. Eisner, E. (2004). El arte y la creación de la mente. Barcelona: Paidós. 
Eisner, E., \& Day, M. (2004). Handbook of Research and Policy in Art Education. London, New Jersey: Lawrence Erlbaum Associates Publishers.

Freedman, K. (2006). Enseñar la cultura visual. Barcelona: Octaedro.

Hardy, T. (2010). Art Education in a Postmodern World. Bristol: Intellect.

Jay, M. (2007). Ojos abatidos. La denigración de la visión en el pensamiento francés del siglo XX. Madrid: Akal.

Jiménez, L., Aguirre, I., \& Pimentel, L. (2009). Educación artística, cultura y ciudadanía. Madrid: OEI y Fundación Santillana.

Joyce, B., Weil, M., \& Calhoun, E. (2002). Modelos de Enseñanza. Barcelona: Gedisa.

Marín, R. (1997). Enseñanza y aprendizaje en Bellas Artes: una revisión de los cuatro modelos históricos desde una perspectiva contemporánea. Revista Arte, individuo y sociedad, 9, 55-77.

Osborne, P. (2010). El arte más allá de la estética. Murcia: CENDEAC.

Vaughn, K., \& Winner, E. (2000). SAT Scores of Students Who Study the Arts: What We Can and Cannot Conclude about the Association. Journal of Aesthetic Education, 34(3/4), Special Issue: The Arts and Academic Achievement: What the Evidence Shows, 77-89. Recuperado de https:// www2.bc.edu/ winner/pdf/satreap.pdf 